\title{
PRETOS E PARDOS, UNI-VOS. OS DESAFIOS DE(O) SER NEGRO NO BRASIL DO SÉCULO XXI.
}

Gabriel Pinheiro de Siqueira Gomes ${ }^{1}$

\begin{abstract}
Resumo
Este artigo pretende estabelecer um debate sobre o conceito de raça no Brasil que vivemos, através de uma leitura dos clássicos acadêmicos e militantes do Movimento Negro. Deste modo, trata-se de retomar o debate apresentado a duras penas por pensadores comprometidos com a causa negra no Brasil. Os eixos do debate proposto no artigo são o histórico do conceito de raça utilizado no Brasil nas últimas décadas, breve abordagem sobre os censos nacionais; análise das transformações e disputa pelas políticas públicas no âmbito do Estado; por fim, uma observação sobre o conceito de raça/cor adotado pelo Instituto Brasileiro de Geografia Estatística (IBGE) no âmbito da Constituição Cidadã de 1988 como resultado e processo de luta organizada da militância acadêmica e política da negritude nos últimos 40 anos.
\end{abstract}

Palavras-chave: Educação; Raça; Racismo; Democracia racial; Pretos e pardos; negros

\section{BLACK AND BROWN, UNITE. THE CHALLENGES OF BEING BLACK IN 21st CENTURY BRAZIL}

\begin{abstract}
This article intends to establish a debate about the concept of race in Brazil that we live, through a reading of the academic and militant classics of the Black Movement. Thus, it is a question of resuming the debate presented with great difficulty by thinkers committed to the black cause in Brazil. The axes of the debate proposed in the article are the history of the concept of race used in Brazil in recent decades, a brief approach on national censuses; analysis of transformations and dispute over public policies within the State; finally, an observation about the concept of race / color adopted by the Brazilian Institute

${ }^{1}$ Mestre e doutorando pelo Programa de Políticas Públicas e Formação Humana (PPFH UERJ). Membro da coordenação do Projeto Ações Afirmativas e Políticas Públicas e Programa Desenvolvimento e Educação Theotonio dos Santos (ProDE-TS - UERJ). Endereço eletrônico: gabrielsiqueira19@hotmail.com
\end{abstract}


of Statistical Geography (IBGE) within the scope of the Citizen Constitution of 1988 as a result and process of organized struggle of academic and political activism of blackness in the last 40 years.

Keywords: Education; Breed; Racism; Racial democracy; Black and brown; black.

\section{Introdução}

\section{“Relembrando Palmares"}

Alguns historiadores, entre eles Décio Freitas, acreditam que em 1655 nascia Zumbi dos Palmares. Homem negro, livre, natural da Serra da Barriga, possivelmente do mocambo de Macaco, considerado a capital do Palmares. Àquela altura, Macaco já tinha 6 mil habitantes, quase empate técnico com Recife, capital da Capitania de Pernambuco, que tinha 8 mil residentes. Dito isso, concluímos que Palmares era um conjunto de cidades que poderia ser equiparado às principais capitais da colônia.

Zumbi, assim como gerações daquele quilombo, nasceu livre. Alguns palmarinos, inclusive, viveram e morreram sem sequer conhecer a escravidão. Afinal, o quilombo durou quase um século, desde os primeiros relatos em 1604 até a morte de Zumbi em 1695. Contudo, este artigo trata de Palmares também, ainda que na lembrança. Consideramos o Quilombo marco histórico da chegada e resistência da cultura afro-brasileira. Palmares é o marco fundacional da luta de libertação no continente. Por isso, então, começar narrando parte dessa epopeia brasileira, relacionando com nosso tema central.

Alguns pontos principais vão dialogar com este artigo, descortinando os primeiros conceitos a serem desmistificados. A dificuldade de compreensão do racismo assimilacionista brasileiro e da categoria negro como a soma dos autodeclarados pretos e pardos por parte do movimento negro de tradição identitária ou pós-moderna pode ser recuperada com riqueza de exemplos na trajetória do primeiro e maior quilombo do continente. A partir daí daremos o ponta pé inicial da construção deste artigo. 
Primeiramente, Palmares nos mostra que é possível vencer. Trata-se de um caso de vitória, pois o quilombo durou quase 100 anos, lutando contra a maior potência daquele século, Portugal. Se fizermos uma comparação, a monarquia brasileira e Palmares teriam uma duração semelhante.

Em segundo lugar, não menos importante, Palmares nos mostra a diversidade do povo negro desde o princípio da história do Brasil contada a partir da conquista europeia. O conjunto da população palmarista era de origem bastante variada. Advindo das diferentes Áfricas ${ }^{2}$, predominavam quilombolas de Angola e Guiné, mas havia muitos ex-escravos nascidos no Brasil, mais tarde chamados de crioulos. Com o passar do tempo, vários quilombolas já nasciam nos mocambos de Palmares, como é o caso de Zumbi, nascido em 1655. Além dos africanos ou afrodescendentes, também havia indígenas em Palmares, como indicam os nomes de alguns quilombolas, mencionados como tapuias, por exemplo ${ }^{3}$.

É desta questão que partimos para o título deste artigo, provocando o debate sobre o que é ser negro no Brasil ou quem são os negros e negras brasileiros na história e na atualidade.

Vamos observar no artigo quem são os homens e mulheres negros no Brasil, a partir da construção das categorias preto e pardo pelo Instituto Brasileiro de Geografia e Estatística - IBGE. Segundo o mesmo, a soma dos

\footnotetext{
${ }^{2}$ Predominavam africanos do grupo de língua bantu, mas havia zulus do sul da áfrica e até da região conhecida hoje como Moçambique.

${ }^{3}$ Sobre Palmares, entre a bibliografia clássica e aquela mais recente destacamos: CARNEIRO, Edison. O quilombo de Palmares. 4th ed. São Paulo: Companhia Editora Nacional, 1988; FREITAS, Décio. Palmares: a guerra dos escravos. 3a ed., Rio de Janeiro: Graal, 1981; FUNARI, Pedro Paulo A. \& ORSER, Jr., Charles E. "Pesquisa arqueológica inicial em Palmares", Estudos Ibero-Americanos, Porto Alegre, Volume 18, número 2, 1994, pp. 53-69; "A Arqueologia de Palmares -- Sua contribuição para o conhecimento da história da cultura afro-americana: In: REIS, João José \& GOMES, Flávio dos Santos. Liberdade por um fio. História dos Quilombos no Brasil. São Paulo, Cia. das Letras, 1996, pp. 26-51; "'A 'República de Palmares' e a Arqueologia da Serra da Barriga", Revista USP, número 28, 1995-6, pp. 6-13; "Novas perspectivas abertas pela Arqueologia na Serra da Barriga", In: SCHWARCZ, Lilía Moritz \& REIS, Letícia Vidor de Sousa. (Orgs.) Negras Imagens: Escravidão e Cultura no Brasil, São Paulo, EDUSP, 1996, pp. 139-151; FUNARI, Pedro Paulo A. \& ORSER, Jr., Charles E. "Pesquisa arqueológica inicial em Palmares", Estudos IberoAmericanos, Porto Alegre, Volume 18, número 2, 1994; PRICE, Richard. "Palmares como poderia ter sido. IN: REIS, João José \& GOMES, Flávio dos Santos. Liberdade por um fio..., pp. 60- 80 SCHWARTZ, Stuart B. "Mocambos, quilombos e Palmares: a resistência escrava no Brasil colonial". In: Estudos Econômicos. São Paulo:
} 
autodeclarados pretos e pardos forma a população negra no Brasil. Deste marco que começaremos nossa análise.

\section{Questões deste breve estudo}

Há, no Brasil, a possibilidade de ascendência social oferecida pelo diploma de curso superior, fato que até transforma muitos estudantes, inclusive cotistas, em defensores da ordem institucional. Temos assistido algo semelhante com estudantes negros formados pela UERJ, alguns deles até atuam no movimento negro e prestam serviço a causa, mas de forma incipiente e liberal.

Ou seja, parte do movimento negro, da qual temos críticas, tem agido de forma coletiva ou individual na direção em que o sistema os posiciona. Especificamente, estes sujeitos e grupos defendem ascensão social dos negros e negras dentro da ordem capitalista dependente brasileira em acordo com fração bem pequena da nossa elite, pois a maior parte delas segue com pensamento colonial escravista.

Enquanto isso, a maioria dos negros vive na miséria ou vem sendo massacrada pelas polícias e ausência de Estado nos territórios onde se concentram pretos e pardos. Um núcleo de negros com diploma, bem-sucedidos nas redes sociais e nas artes aderiu ao discurso dominante que permite a nós migalhas que caíram da mesa. Algumas mulheres negras entraram nas universidades e outros espaços de poder, assim como homens negros que sobreviveram ao genocídio ocuparam locais de certo prestígio e atingiram outro patamar econômico, a revelia do massacre que o Estado brasileiro segue operando nas periferias.

Estes dados de ascensão são irrisórios, conforme tem se verificado nos estudos demográficos sobre desigualdade racial no $\mathrm{Brasil}^{4}$, mas amplamente divulgados pelo status quo e comemorado pela nossa gente, ainda que o genocídio siga incólume. Obviamente, que estes que comemoram ou saúdam não são os responsáveis sobre o massacre, muito menos temos a intenção de responsabilizá-los, mas queremos, através do artigo, discutir os entendimentos na raiz da questão racial. Ir a raiz do problema, não administrar ascensão de alguns homens e mulheres negras e parar na noção de representatividade abstrata, enquanto a miséria e genocídio continuam atravessando a maioria negra do país.

\footnotetext{
${ }^{4}$ https://biblioteca.ibge.gov.br/visualizacao/livros/liv101681 informativo.pdf Acessado em: 30/10/2020
} 
A universidade brasileira é decisiva no jogo das oportunidades e obstáculos sociais. Desta forma, as políticas afirmativas não só proporcionam um diploma de curso superior, como também, a partir desse, a maior chance de acessar espaços sociais e econômicos não cogitados anteriormente. Os cotistas conquistaram também o poder da palavra dentro e fora da academia, ainda sobre signos da brancura como currículos acadêmicos epistemologicamente eurocêntricos. Um quadro social justificado com a presença de um Lazaro Ramos ou uma Thais Araújo e mais meia dúzia de negros nos espaços de mídia, enquanto a massa afro-brasileira vive a margem da sociedade, não nos parece razoável.

A presença de estudantes pretos e pardos chocou e choca, principalmente, nas salas e corredores da universidade, onde já é um fator de disputa pela identidade e pela construção de um conhecimento que dê conta de explicar, entre outras coisas, os mecanismos responsáveis pela manutenção das desigualdades socioeconômicas e raciais no Brasil ${ }^{5}$.

O número de estudantes pretos e pardos triplicou na última década de 10,2\%, em 2001, para 35,8\%, em 2011 de acordo com a Síntese de Indicadores Sociais - SIS ${ }^{6}$ (2012). Além do último censo, tivemos uma avanço no quesito da autodeclaração da comunidade negra brasileira, verificada na pesquisa Nacional por Amostra de Domicílios (PNAD) 2019, 42,7\% dos brasileiros se declararam como brancos, $46,8 \%$ como pardos, $9,4 \%$ como pretos e $1,1 \%$ como amarelos ou indígenas ${ }^{7}$. Entretanto, nosso problema está colocado não para minoria branca acuada, mas sim pelo reconhecimento do nosso grupo, projeto histórico, perspectivas e propostas para a sociedade.

Tudo isso é possível nos marcos da sociedade que temos, o genocídio continua, apesar dos esforços empreendidos. Por outro lado, nada disso invalida as conquistas a partir da luta. Novamente, queremos ir à raiz das questões começando pela construção do conceito raça/cor, suas tecnologias e a disputa do mesmo entre resistência e assimilação. Pretos e partos do Brasil, uni-vos!

\footnotetext{
${ }^{5}$ Recentemente Renato Emerson dos Santos considerou três impactos, fruto das Cotas na UERJ: um político, um estético e um epistemológico. Ver SANTOS (2006).

${ }^{6}$ Disponível em: $<$ http://censo2010.ibge.gov.br/pt/noticias$\underline{\text { censo }}$ ?view $=$ noticia\&id $=1$ \&idnoticia $=2268 \&$ busca $=1 \& \mathrm{t}=$ sis -2012 -acesso-jovens-pretospardos-universidade-triplicou-dez-anos $>$ Acesso em 04/06/2020. 7 https://educa.ibge.gov.br/jovens/conheca-o-brasil/populacao/18319-cor-ou-raca.html Acessado em 31/10/2020
} 


\section{O conceito de raça/cor ontem e hoje - Entre a resistência e a assimilação}

Por que pretos e pardos? Pretos e pardos são os negros do Brasil? De onde veio essa história que pretos e pardos somados dão na população negra? Quem, como, quando e onde foram construídos esses conceitos e o mais importante o porquê deles. Juntar pretos e pardos na categoria negro pode ser resistência ou assimilação? Tentaremos responder algumas questões e apontar algumas soluções para o nosso dilema. Vamos começar do começo, ou seja, dos clássicos.

Munanga (2006) relendo o conceito de raça afirma que tem origem do italiano razza, que por sua vez veio do latim ratio, que significa sorte, categoria, espécie. Este é o significado etimológico do conceito, inclusive nos registros da história das ciências naturais. Primeiramente, este conceito foi usado na Zoologia e na Botânica para classificar as espécies animais e vegetais. $\mathrm{O}$ naturalista sueco, Carl Von Linné, conhecido em português como Lineu (1707-1778), nesse sentido, utilizou para classificar as plantas em 24 raças ou classes, classificação hoje superada totalmente.

O conceito de raça, assim como muitos conceitos, necessita de um recorte no campo semântico e na dimensão histórica e temporal. No latim medieval, o conceito de raça passou a denominar descendência, uma espécie de linhagem, de modo que um grupo de pessoa que têm um ancestral comum e que, possuem algumas características físicas em comum.

Em 1684, o francês François Bernier emprega o termo naquilo que viria a ser o sentido moderno da palavra, para classificar a diversidade humana, isto é, em grupos fisicamente contrastados, denominados "raças". Fato este devido ao advento do alargamento do mundo conhecido, através das grandes navegações e o encontro de continentes e povos distintos. 0 exemplo deste conceito ratifica Munanga (2006), também foi aplicado na própria Europa.

Nota-se, nesse sentido, o transporte do conceito de raças "puras" da Botânica e da Zoologia no sentido de legitimar as relações de sujeição entre 
diferentes setores sociais, neste caso, sem que houvesse distinções morfobiológicas claras entre os indivíduos pertencentes a ambas as classes.

Com a expansão marítima e comercial e a chegada de portugueses no continente americano é que vão surgir, em locais da África e Ásia, distinções físicas entre os povos do Velho Continente e da parte deles com o restante do mundo. A noção de raça do século XVI permanece até a atualidade, contudo não mais em termos científicos, conforme se nota no senso comum (WOLFE, apud MEDEIROS, 2004, p.33).

A invenção histórica "raça" está calcada na aplicação de um termo advindo das ciências naturais para as relações humanas e sociais, que irá considerar as características intelectuais e morais de um dado grupo como consequências diretas de suas características físicas ou biológicas.

A professora Gesiela Iensue (2010) advoga que o conceito de raças permanece no seio de diversos debates e no imaginário popular, pois do ponto de vista científico-biológico já está superado:

(...) embora a biologia contemporânea seja praticamente unânime na inadmissão de um conceito científico de raça, isso não quer significar, que em termos de relações sociais, o termo "raça", não desempenhe um papel relevante no combate à discriminação e na promoção de instrumentos que visem à equalização de oportunidades (IENSUE, 2010, p. 90).

A raça no sentido sociológico, ou seja, a raça no imaginário do racista não é exclusivamente um grupo definido pelos traços físicos. Munanga (2006) vai chamar de raças sociais, uma vez que o conceito científico de raças é invalidado, ou melhor, considera-se inaplicável aos seres humanos.

Quanto a isso, ainda, segundo Munanga (2006), é preciso enfatizar que são conceitos interligados a estruturas ideológicas de poder, dominação e hierarquização, pois já foram articulados na produção e perpetuação de sistemas sociais opressores e excludentes. Houve a sugestão de que o conceito de raça fosse banido dos dicionários e dos textos científicos por parte de alguns biólogos antirracistas.

Hédio Silva Jr contextualiza raça do ponto de vista biológico:

Raça, uma categoria da biologia, designa um conjunto de aspectos biofisiológicos cambiantes, que diferenciam elementos da mesma espécie. Por exemplo, na espécie dos felinos ou dos caninos, temos as raças de gatos ou cães com aspectos bio-fisiologicamente variáveis, porém, isolados nas suas 
raças e reciprocamente hostis em ambientes comuns. (...) Desde os anos de [19]50, após estudos realizados pela Organização das Nações Unidas, num empreendimento mundial desenvolvido por geneticistas, antropólogos, cientistas sociais, biológicos e biofisiologistas, o termo raça é considerado, ao menos sob o prisma científico, inaplicável a seres humanos. A conclusão destes estudos é de que os seres humanos formam um continuum de variações da aparência, no interior da mesma espécie, sem que estas variações afetem a possibilidade de convivência e reprodução de outros seres humanos. (SILVA JR., 2002, p.14)

Enquanto elemento normativo, Fabiano Augusto Martins Silveira (2007) discorre:

(...) a partícula raça cumpre a função de detectar os grupos aos quais se aplicam os conectores preconceito e discriminação. Tem-se, com efeito, "preconceito de raça" e "discriminação de raça". Vale dizer, preconceito e discriminação que recaem sobre determinadas parcelas pelo fato de serem apontadas como racialmente inferiores (ou simplesmente como raças). (SILVEIRA, 2007, p. 83-84)

Neste contexto, a concepção de raça, verificada pelo viés histórico e político, versa sobre as diferenças físicas e/ou culturais eventualmente existentes entre agrupamentos humanos. Contudo, podemos perceber a presença de um discurso superficial sobre as raças, pelo menos no sentido biológico, ou seja, há uma repercussão equivocada do sentido de raça que pode provocar por falsas teorias, narrações, crenças e propagandas ideológicas. Logo, em muitas ocasiões, a palavra raça é substancializada no senso comum, num sentido vulgar, permitindo aqueles grupos historicamente estigmatizados pelo preconceito e discriminação raciais.

Especificamente no Brasil, a cor da pele é considerada como critério para diferenciar subjetivamente a raça, tendo em vista que a mesma também pode variar de acordo com a aparência, a tonalidade da pele. Segundo Ribeiro (2006), por exemplo:

(...) a característica distintiva do racismo brasileiro é que ele não incide sobre a origem racial das pessoas, mas sobre a cor de sua pele. Nessa escala, negro é o negro retinto, o mulato já é o pardo e como tal meio branco, e se a pele é um pouco mais clara, já passa a incorporar a comunidade branca. (RIBEIRO, 2006, p.225)

Retomando Silveira podemos compreender que:

A partícula cor exerce, do ponto de vista legal, como elemento normativo dos crimes de racismo, a mesma função da raça, isto é, particularizar aqueles agrupamentos humanos corados pelo preconceito e discriminação (as pessoas de cor), ligando-se aos referidos conectores. Há, entre raça e cor, uma 
relação de especialidade, um plus, revelando que o legislador preferiu a abundância à escassez. 0 máximo que se pode afirmar é que a expressão "preconceito de cor" é utilizada, no senso comum, mais especificamente, para designar o preconceito dirigido à população afrodescendente, ou seja, como elemento caracterizador de uma manifestação particular do racismo, ainda que a expressão "preconceito de raça" seja potencialmente mais abrangente. (SILVEIRA, 2007, p. 88)

Diante disso, vamos observar a construção dada pelo IBGE na forma de acúmulo político, científico e acadêmico de amplos setores ligados ao movimento negro desde a década de 1980.

O Instituto Brasileiro de Geografia e Estatística - IBGE define raça/cor ${ }^{8}$ de acordo com a declaração fornecida pelas pessoas, no momento da entrevista, ou, no caso de concursos públicos, no ato da inscrição, segundo as seguintes opções: branca, preta, amarela, parda ou indígena. Em diversos momentos do artigo, lembramos as ações afirmativas como elemento para a discussão, uma vez que as cotas para negros em universidades brasileiras, para o bem e para o mal, potencializaram este debate novamente no seio da sociedade brasileira.

Essa definição gera diversas polêmicas, pois no Brasil o racismo fundamentado na ideologia da democracia racial colabora para a resistência de negros e pardos na autoidentificação de sua cor/raça ${ }^{9}$. Como temos analisado, o racismo de assimilação busca desracializar a sociedade brasileira até a página 2 (dois), isto é, quando convêm as elites.

Afinal, não somos racistas é o ápice da produção neoliberal militante em favor deste projeto, escrito pelo Ali Kamel diretor de jornalismo da maior emissora do país. Em 2020 acompanhamos atentos as grandes manifestações raciais nos EUA, em função da morte, desta vez televisionada, de negros por forças policiais. No Brasil, os dois casos mais repercutidos de racismo no

\footnotetext{
8 Trata-se do modo como o IBGE define contemporaneamente os padrões de declaração, entretanto este padrão é fruto de uma discussão secular em torno do tema. 0 processo pelo qual esta discussão perpassa será evidenciado mais a frente.

${ }^{9}$ Nascimento (1978) versa sobre o problema da autodeclaração, pois em sua visão há um genocídio estatístico sobre a população negra nos censos brasileiros
} 
Plaza Shopping em Niterói (RJ) ${ }^{10}$ e Valinhos (SP) ${ }^{11}$ logo após a morte do George Floyd foram de jovens cujo fenótipo seria semelhante ao que popularmente chamamos de pardo. Contudo, nenhuma das teorias do colorismo ou da passabilidade ${ }^{12}$ de negros de pele clara funcionou para os dois casos. Afinal, o que seu viu foram clássicos casos de racismo, um deles ocasionando espancamento do jovem que comprava um relógio para o pai.

Vejamos as categorias do censo, finalmente. Trata-se de cinco categorias de pertencimento racial presente nos censos, questionários e formulários pelo país. É necessário pensar relações raciais e, para isso, as ditas categorias mostram-se indispensáveis.

O ponto de chegada destas cinco categorias não pode ser considerado somente consenso ou procedimento de caráter técnico, a realização dos censos demográficos reflete, também, projetos políticos que se manifestam nas perguntas elaboradas, na metodologia empregada e, evidentemente, nas opções de respostas que são fornecidas.

Os pesquisadores brasileiros constroem a classificação de negro com base nos dados de cor da pele fornecidos pelo IBGE. Com base nessa lógica, a população negra seria composta a partir da soma das pessoas que se autodeclaram pardas e pretas. A lógica em questão usa a categoria "preto" como classificação de cor ou raça desde a primeira pesquisa de censo demográfico em 1872, conforme Nota Técnica sobre o Histórico da investigação sobre cor ou raça nas pesquisas domiciliares do IBGE13.

\footnotetext{
${ }^{10} \mathrm{https} / /$ noticias.uol.com.br/cotidiano/ultimas-noticias/2020/08/07/jovem-negro-eagredido-no-rio-apos-comprar-relogio-de-r-300-para-o-pai.htm

Acessado em 20/10/2020

${ }^{11}$ https://noticias.uol.com.br/cotidiano/ultimas-noticias/2020/08/07/motoboy-e-alvode-ofensas-racistas-voce-nunca-vai-ter-nada-diz-agressor.htm?cmpid=copiaecola Acessado em 20/10/2020

12 Não vamos aprofundar essas categorias (colorismo e passabilidade) neste artigo, temos uma posição contrária a construção identitária e pós-moderna da mesma, pois precisamos aprofundar a questão dos pretos e pardos e do racismo brasileiro. Cito aqui um texto para os interessados. https://www.geledes.org.br/sobre-colorismo-privilegios-e-identidaderacial/?gclid=Cj0KCQjwufn8BRCwARIsAKzP696GnYN4XwyMHoXnGUcoCBmr7PEWsMSUU r-v9GMBeTRM6E04tRq_zU4aAuGSEALw wcB

Acesso em 31/10/2020

${ }^{13}$ Disponível em:

<http://www.ibge.gov.br/home/estatistica/populacao/caracteristicas raciais/notas tecni cas.pdf $>$ Acessado 05/07/2020
} 
Com base em Osório (2003), a partir de uma recuperação histórica14, torna-se possível compreender o processo em que está circunscrito a questão cor ou raça no debate brasileiro e no censo. Em 187215, o primeiro censo brasileiro utilizou as categorias que a sociedade citava no seu cotidiano, desde jornais, anúncios e outros materiais escritos como forma de classificação e até da criação de uma hierarquização racial dos brasileiros. Apenas o censo de 1890 utilizou a categoria mestiço em substituição de pardo. Em 1940 o censo voltou a considerar cor ou raça, quando, em função do fluxo de migração asiática, foi criada a categoria amarela no censo ${ }^{16}$.

Justamente no Censo de 1991, sob reflexo da constituição de 1988, com a adição da categoria indígena, é que a classificação passou a ser de cor ou raça, ganhando suas cinco categorias atuais.

A classificação racial brasileira é única, e reflete preocupações engendradas pela história nacional. Não existe uma classificação internacional para raças ou para etnias. Nos diferentes países, conceitos como etnia, tribo, nação, povo e raça recebem conteúdos locais, pois as bases importantes para a delimitação das fronteiras entre grupos sociais são produzidas pela história de cada sociedade. (OSÓRIO, 2003, P. 19)

\footnotetext{
${ }^{14}$ A classificação cor ou raça utilizada pelo IBGE tem mais de um século de história e debates, tendo uma imensa gama de opções mais complexas e discutíveis como as empregadas por Nina Rodrigues (1988) e presentes nas seções de jornais analisadas por Schwarcz (1987); nota-se que existem termos relacionados à posição no sistema escravocrata: escravo, peça, liberto, livre e forro. 0 emprego dos termos de cor nas notícias de fugas de escravos publicadas pela historiadora L. Schwarcz (1987) tem valor específico bastante interessante para nosso debate. Com as comuns fugas de escravos, tornou-se imperativo caracterizar o fugitivo de forma detalhada para que pudesse ser identificado e devolvido ao seu dono. Essa necessidade leva à elaboração de cores compostas, com outros termos de cor definindo as minúcias do indivíduo, ou com outras categorias de termos étnico-raciais: pardo quase branco, cobre azeviche, crioulo bem preto, preta de angola, preto retinto etc. Altura, compleição, cor e tipo dos cabelos, presença de barba, bem como eventuais marcas deixadas pelos diversos castigos que eram infligidos aos cativos, dentre muitas outras, essas eram as características da cor para identificação destes. Eram acrescentadas também a idade, geralmente aproximada por categorias como moço, moleque, velho; além de informações sobre caráter ou estilo, temperamento, e habilidades pessoais, como o domínio de ofícios, da escrita, da leitura e da aritmética.

15 Os termos preto, pardo e branco eram os mais utilizados já no censo de 1872, o primeiro oficial no Brasil. Esses vocábulos raciais de grande fluência social foram os designadores das categorias da classificação racial no país, porém, além dessas três categorias, no censo de 1872, havia o caboclo, que deveria conter o grupo dos indígenas. As únicas aplicáveis à parcela escrava da população eram as categorias preta e parda, embora, em alguma medida, pudessem também enquadrar pessoas livres de nascimento ou alforriadas. 16 Nunca houve uma categoria específica para indígenas nos censos brasileiros, apenas na década de 1990 foi incluída esta categoria. Cabe salientar que, do Censo de 1940 até o de 1991, a classificação era só de cor.
} 
Esta recuperação histórica da evolução dos censos é necessária para entendermos como a questão raça e cor tem relevância para o debate que faremos, assim como para compreender o contexto e construção da maneira como o povo brasileiro se identificou e foi identificado nos e pelos órgãos oficiais ao longo dos anos.

Isto é, a classificação racial brasileira é única no sentido de que é diferente das classificações de outros países, o que faz que a mesma se constitua como reflexo das preocupações engendradas pela história nacional.

A diversidade é reconhecida pelos órgãos oficiais internacionais que optam por não definir um sistema de classificação universal para ser aplicado, por exemplo, no estudo das desigualdades socioeconômicas e políticas existentes entre os grupos determinados a partir dessas bases. Logo, quando realizadas pesquisas internacionais, as disposições raciais ou étnicas são objetos de interesse, geralmente é empregada segundo as categorias locais utilizadas pelos órgãos oficiais de estatística dos diversos países. 0 exemplo da Demographic and Health Survey é referência, pois quando realiza pesquisa no Brasil, a questão étnica submeteu-se ao sistema classificatório de cor ou raça do IBGE (OSÓRIO, 2003).

Em torno dessas discussões e decisões históricas, o IBGE considera formar a classificação de negros a partir do somatório da população preta e da população parda. Portanto, usar o termo preto não é equivalente a usar a categoria negro, pois esta última pode incluir os pardos. Finalmente, as políticas afirmativas consideram a discussão histórica, estão incluídas no debate das raças e das classificações feitas pelo IBGE, utilizam a classificação de negro conforme o modelo do Instituto. Este fato pode ser apreciado se pensarmos na evolução histórica dos censos brasileiros, juntamente com a discussão racial ocorrida na sociedade desde 1872 até o formato assumido em 1991 no processo de transição democrática do país.

Se por um lado o Iluminismo produz inúmeras reflexões acerca do liberalismo, por outro processa a discussão intensa sobre o conceito das raças humanas. Através do pensamento racional iluminista é que se entendem as taxonomias originadas do reino animal e vegetal, conforme 
Medeiros nos mostra, incluindo os seres humanos, provocando sensação tendenciosa. Os europeus aparecem em posição superior, denominados brancos, enquanto negros, amarelos e vermelhos são racializados como inferiores (MEDEIROS, 2004, P.34).

\section{Raça é discussão, o racismo brasileiro é assimilação}

Uma das características do racismo brasileiro também conhecido como democracia racial brasileira é o assimilacionismo. Por isso, a figura central deste problema está na categoria pardo. Como vimos anteriormente, esta categoria está presente desde o primeiro censo nacional de 1872.

Tereza Cristina N. A. Costa realiza um estudo que apresenta as teorias sociológicas sobre "relações interétnicas" e, a partir da discussão sobre o significado de termos como raça, etnia e cor, que ela observa serem usados indistintamente, desenvolve um estudo sobre as dificuldades do levantamento do quesito cor nos censos. Costa (1974) observou a problemática da inclusão do quesito cor nos censos brasileiros.

As características sui generis do racismo no Brasil, outrora chamado de racismo à brasileira, descrito em suas características sutis e gritantes ao mesmo passo, fora destrinchado por uma literatura clássica da temática negra, cujo pioneiro é o professor Abdias Nascimento, professor emérito da $\mathrm{UERJ}^{17}$.

A democracia racial está ligada a produtos conceituais e termos do tipo assimilação, aculturação, miscigenação, que camuflam, sob uma superfície teórica, a crença intocada na inferioridade dos afro-brasileiros e seus descendentes.

\footnotetext{
${ }^{17}$ Nascimento é um dos idealizadores das Políticas Afirmativas no país, baseadas em ações compensatórias para com a população negra, conforme dito anteriormente. É preciso compreender que tais propostas não nascem de um dia para o outro da cabeça de Nascimento, são frutos de uma discussão e produção científica que iniciaram no autoexílio dele, pois proporcionaram uma convivência ampla com militantes do movimento pelos direitos civis nos Estados Unidos, panafricanistas etc. Tais perspectivas advêm das formulações teóricas sobre as quais ele se debruçou durante anos, incluindo as contribuições de marxistas e panafricanistas do movimento negro norte-americano e das lutas de descolonização do continente africano e asiático, vide conferência de Bandung.
} 
Poderíamos dizer que a democracia racial é uma espécie de síntese dialética de racismo. Um esforço de explicação ou da construção de um entendimento que é ao mesmo tempo acadêmico, militante e social, tendo implicações políticas em termos de redefinição de relações de poder e reflete o racismo já existente na sociedade.

É possível perceber na obra O genocídio do negro brasileiro (1978) que Nascimento opera sobre as categorias mestiçagem e genocídio como fundamentais para sua pesquisa sobre a condição social, econômica e política do negro brasileiro. A mestiçagem pode ser entendida como a imbricação entre a miscigenação, uma forma biológica de intercurso racial e uma espécie de sincretismo cultural que formaria, médio prazo, uma sociedade unirracial e unicultural. Nesta mestiçagem está grande parte do aporte teórico da democracia racial, consequentemente, do embasamento do debate que permeia as ações afirmativas. A ideia de mestiçagem presente na categoria parda logo se torna um mecanismo de disputa, se pensarmos na assimilação como principal carcterística do racismo brasileiro

Nesse sentido, uma espécie de silenciamento do debate, um genocídio acadêmico, científico da temática racial, uma vez que as discussões em volta do tema, ainda que feitas por acadêmicos reconhecidos e indivíduos de produção relevante nos espaços formais de saber, foram impedidos de levar a diante suas pesquisas e considerações.

0 conceito de democracia racial erigiu-se no Brasil a partir de especulações, com o apoio das chamadas ciências históricas, e refletia determinada relação concreta na dinâmica da sociedade brasileira: que negros e brancos têm uma convivência harmônica, e que desfrutam de oportunidades iguais de existência, sem interferência de origens raciais ou étnicas. Ideologia esta formulada por Gilberto Freyre (2004) como se pudesse haver um luso-tropicalismo, onde a ideia de um Brasil sem raças e problemas raciais pudesse florescer, sem a necessidade de ações compensatórias para com as populações um dia escravizadas e seus descendentes. 
Devemos compreender "democracia racial" como significando a metáfora perfeita para designar o racismo estilo brasileiro: não tão óbvio como o racismo nos Estados Unidos e legalizado qual o apartheid da África do Sul, mas eficazmente institucionalizado dos níveis oficiais de governo assim como difuso no tecido social, psicológico, econômico, político e cultural da sociedade do país. Da classificação grosseira dos negros como selvagens e inferiores, ao enaltecimento das virtudes da mistura de sangue como tentativa de erradicação da "mancha negra"; da operatividade do "sincretismo" religioso; à abolição legal da questão negra através da Lei de Segurança Nacional e da omissão censitária - manipulando todos esses métodos e recursos - a história não oficial do Brasil registra o longo e antigo genocídio que se vem perpetrando contra o afro-brasileiro. Monstruosa máquina ironicamente designada "democracia racial" que só concede aos negros um único "privilégio": aquele de se tornarem brancos, por dentro e por fora. A palavra senha desse imperialismo da brancura, e do capitalismo que lhe é inerente, responde a apelidos bastardos como assimilação, aculturação, miscigenação; mas sabemos que embaixo da superfície teórica permanece intocada a crença na inferioridade do africano e seus descendentes. (NASCIMENTO, 1978, p. 93)

Adeptos desta teoria expuseram ao mundo um novo modelo de sociedade, baseada na superioridade racial portuguesa, leia-se branca, e em sua importância em relação à concepção de uma civilização avançada, fundada na mestiçagem que, neste caso, é aquela que embranquece e assimila as outras culturas. No caso brasileiro, a intenção é assimilar os pardos. Um racismo assimilacionista extremamente hábil vem sendo constantemente aperfeiçoado como tecnologia de destruição da raça negra no país.

Os pardos não devem se considerar negros para não construir uma possível maioria econômica e politicamente excluída, por outro lado não são aceitos como brancos. Sofrem o racismo em suas mais diversas formas, seja pela exclusão educacional, de saúde e/ou geográfica, mas também não escapam do genocídio policial. Os corpos no IML predominantemente negros são chamados de pardos, como lembrou recentemente Sueli Carneiro ${ }^{18}$. Todos aqueles que são notadamente negros ou não querem ser brancos, dos mais claros aos mais retintos, ainda que estes últimos tenham maiores dificuldades. Afinal, o mundo é dos brancos. Os pardos entram neste debate. Estão no cerne da tecnologia de controle da massa negra no Brasil.

${ }^{18} \mathrm{https://twitter.com/oieusoucamila/status/1287390475536785409} \mathrm{Acessado}$ $20 / 10 / 2020$ 
Gilberto Freyre (2004) cunhou alguns rodeios que visavam racionalizar as relações raciais no país. 0 termo morenidade seria o maior exemplo desta racionalização que tem como objetivo, segundo Nascimento (1978) o desaparecimento inapelável do descendente de africano, tanto fisicamente quanto espiritualmente, através do intenso e malicioso processo de embranquecer a pele negra e a cultura do negro. Este é o racismo brasileiro que embranquece por conveniência, sem nunca aceitar totalmente aqueles que não quer pensando e agindo como negros.

O fato é que a discussão mais uma vez está no centro do debate da democracia racial, que Nascimento tenta desconstruir em duas das suas principais obras O Genocídio do Negro Brasileiro e O quilombismo (1980).

A metarraça significaria o além-raça, suposta base de consciência brasileira. Atingiríamos neste ponto do nosso desenvolvimento demográfico uma síntese suprema: a morenidade metarracial, oposta aos conceitos fornecidos por arianismo e negritude (NASCIMENTO, 1978 p.44).

A elite intelectual dominante ao eleger o mulato como símbolo de brasilidade e sustentáculo da democracia racial, estabelece o primeiro degrau na escala daquilo que chama de branquificação sistemática do povo brasileiro. Trata-se de uma branquificação pela metade, não podemos nos declarar negros, mas também não somos aceitos no mundo dos brancos.

Este é processo progressivo de clareamento da população brasileira, com o avanço do elemento mulato ou pardo fora do grupo dos negros.

Contudo, não se percebe qualquer tipo de vantagem no status social, pois a posição do mulato se equivale àquela do negro, pois ambos são vítimas de igual desprezo, idêntico preconceito e discriminação, cercado pelo mesmo desdém da sociedade brasileira, institucionalmente branca ${ }^{19}$.

0 que chamamos de processo de um racismo mascarado é negar ao negro a possibilidade de se autodefinir, desfalcando-lhe os meios de identificação racial. É exatamente numa espécie de negação do direito do autorreconhecimento identitário que se encontra a chave da dominação e

\footnotetext{
${ }^{19}$ Basta verificar o já citado o Mapa das Desigualdades Sociais por Cor ou Raça no Brasil feito pelo IBGE https://biblioteca.ibge.gov.br/visualizacao/livros/liv101681_informativo.pdf Acessado em 31/10/2020
} 
exploração da população negra no Brasil, uma vez que serve como fator que imobiliza e desmotiva qualquer tipo ou grau de organização que vise questionar a real condição deste segmento.

O Estado brasileiro construiu durante longo período uma imagem que visou sempre negar e suprimir a perspectiva racial como fator determinante em sua dinâmica social, política e pública. É neste fato que residirá nossa articulação entre os conceitos aqui citados e o caminhar do trabalho, no que se refere às políticas afirmativas na modalidade de cotas. Contudo, segundo Nascimento, criou-se assim um modelo que esteve, e acreditamos que continua a estar, na contramão da realidade nacional cotidiana.

A situação desfavorável e desigual a que foram submetidos os afrobrasileiros ao longo da história não é apresentada nem pela bibliografia mais contemporânea ao cenário internacional, assim como não atinge somente pretos retintos. A policromática raça negra brasileira é atravessada pelo racismo do mais escuro ao mais claro. Todos nós que fomos chamados de pardos, mulatos, morenos ou qualquer coisa do tipo, fomos parados pela polícia, vivemos sempre do trabalhado ou da ausência do mesmo como possibilidade. É realmente necessário opor mais claros e mais escuros?

Em alguns momentos, os censos brasileiros, como falamos anteriormente, chegaram a aferir mais de 130 classificações raciais, do mulato à morena jambo. Afinal, pretos são apenas $9 \%$ da população brasileira?

A construção da categoria negro como resultado da somatória de pretos e pardos envolveu um trabalho da militância negra de engenharia política, uma extensa produção acadêmica sobre desigualdades raciais no Brasil a similitude de condições sociais e econômicas compartilhadas por esse grupo. Além do extenso abismo entre essas duas categorias da parte de cima da tabela, onde fica a hegemonia branca. Estabeleceu-se uma crítica a partição da nossa identidade negra. A mestiçagem foi projeto de branqueamento e desintegração da raça negra sem dar tiros de fuzil. Seu principal resultado foi o fracionamento da identidade negra, impedindo uma unidade entre pardos e pretos enquanto maioria social e política. 
O imperialismo da brancura, termo utilizado pelo autor (1978), marcado pelo capitalismo que lhe é inerente, nos permite concluir que o racismo é parte integrante do sistema capitalista. Para ele, o racismo estrutural e institucional brasileiro, não pode ser entendido e pesquisado descolado do sistema político e econômico. Nascimento em seus ensaios no livro $O$ quilombismo, afirma:

(...) os homens e as mulheres da África, e de descendência africana, têm tido uma coisa em comum - uma experiência de descriminação e humilhação imposta sobre eles por causa de sua origem africana. Sua cor foi transformada tanto na marca como na causa de sua pobreza, sua humilhação e sua opressão (NEYRERE, apud NASCIMENTO, 1980, p. 17).

No entanto, para Nascimento é necessário justamente negar os termos da morenidade, pois nele que se encontra o ápice do processo ao qual ele define como genocídio. Isto se dá através da implementação organizada de uma mestiçagem programada, conforme dito anteriormente, que objetiva eliminar sistematicamente o elemento negro da dinâmica social brasileira.

Podemos ler as páginas da história da humanidade abertas diante de nós, e a lição fundamental que nos transmitem é de uma enorme fraude teórica e ideológica articulada para permitir que a supremacia ário-euro-norteamericana pudesse consumar sua imposição sobre nós. (NASCIMENTO, 1980, p. 22).

O racismo estrutural espraiado na sociedade brasileira se faz presente nas instituições e políticas públicas, neste quesito, outra vez, Nascimento se coloca de forma pioneira:

Além dos órgãos de poder - o governo, as leis, o capital, as forças armadas, a política - as classes dominantes brancas têm à sua disposição poderosos implementos de controle social e cultural: o sistema educativo, as várias formas de comunicação de massa - a imprensa, o rádio, a televisão - a produção literária. Todos esses instrumentos estão a serviço dos interesses das classes no poder e são usados para destruir o negro como pessoa e como criador e condutor de uma cultura própria. (NASCIMENTO, 2002, p. 142).

Os negros e negras do Brasil passaram a ter acesso à escola somente a partir de 1930, assim mesmo de forma muito reduzida, conforme nos revelam os dados estatísticos do censo de 1950, em que todos os alunos atendidos na escola primária, somente 4.016 eram de negros. Na escola secundária, menos de $1 \%$ e, somente cerca de $0,25 \%$ nas universidades. Antes disso, na República Velha e durante o período colonial, nem os negros libertos eram aceitos pelo sistema educacional e pela própria sociedade, o que causou sequelas comprometedoras na formação das gerações afrodescendentes. (SOUZA, 2004, p. 45) 
Munanga verifica que a tendência de os pardos tentarem escolher o grupo dos brancos é legítimo e até uma tentativa de sobrevivência. Afinal, estamos no mundo dos brancos. Daí a necessidade de inverter o jogo proposto pelo racismo brasileiro.

Uma tal sociedade seria construída segundo o modelo hegemônico racial e cultural branco ao qual deveriam ser assimiladas todas as outras raças e suas respectivas produções culturais. 0 que subentende o genocídio e o etnocídio de todas as diferenças para criar uma nova raça e uma civilização, ou melhor, uma verdadeira raça e uma verdadeira civilização brasileiras, resultantes da mescla e da síntese das contribuições dos stocks raciais originais. Em nenhum momento se discutiu a possibilidade de consolidação de uma sociedade plural em termos de futuro, já que o Brasil nasceu historicamente plural (MUNANGA, 2006, p.97).

\section{0 preconceito racial de marca e a assimilacionismo}

A característica que distingue o nosso racismo, é que ele não incide sobre a origem racial das pessoas, mas sobre a cor de sua pele. É fruto de uma situação em que a mestiçagem é antes louvada que punida, o que não chega a ser como uma democracia racial, como muitos quiseram, e como, até hoje, as ideologias liberais tentam nos forçar a acreditar. Por outro lado, apresenta formas até mais violentas e intolerantes que regimes onde há políticas de apartheid, uma vez que em conjunturas assimilacionistas a negritude se dilui em inúmeras gradações, que quebram a solidariedade e o poder de combate (RIBEIRO, 2006, p. 225-226).

Ribeiro (2006) ao falar sobre o racismo, se apoia nas teses do professor Oracy Nogueira (NOGUEIRA, 1985) sobre preconceito racial de marca, isto é, o preconceito de cor (NOGUEIRA, 1985).

Esse preconceito, diferente do de raça, e irredutível ao de classe pois atingiria mesmo pessoas (negras e pardas) das chamadas 'classes superiores' - varia em intensidade "conforme a nuança que este atributo pode assumir: quanto mais escuro é o indivíduo, mais ele sofre as consequências do preconceito de cor (NOGUEIRA., 1985, p. 124).

0 racismo brasileiro, segundo Ribeiro (2006), é postulado à medida que se pode reconhecer o negro pelo fenótipo. Diferentemente de países como os Estados Unidos, onde o racismo é verificado pela origem racial, no Brasil, Nogueira (1985) cunhou o termo preconceito racial de marca que é, como 
vimos, pilar de sustentação da análise de Ribeiro (2006) sobre o racismo. 0 preconceito racial de origem discrimina e prejudica os que descendem do grupo discriminado, independentemente se as pessoas trazem em sua aparência física os traços de seu grupo de origem. Em caso de miscigenação, o produto do cruzamento é identificado com o grupo discriminado, mesmo se fisicamente se caracterize pela aparência do grupo discriminador. Entretanto, a forma de atuação do preconceito racial de origem, a exclusão incondicional dos membros do grupo atingido, em relação a situações ou recursos pelos quais venham a competir com os membros do grupo discriminador (NOGUEIRA, 1985, p.79), por si já reduz a probabilidade de ocorrerem uniões inter-raciais. Como a exclusão é incondicional, a delimitação do grupo discriminado é rígida: nos Estados Unidos da década de 1950, por exemplo, qualquer pessoa que tivesse um antepassado negro conhecido ou localizável (ou que a comunidade considerasse negro) seria também negra, mesmo que, numa situação extrema, a pessoa tivesse a pele alva e fosse inteiramente branca na aparência.

No preconceito racial de marca, por outro lado, a origem não importa, apenas quantos traços ou marcas do fenótipo do grupo discriminado são portados pela vítima potencial. 0 indivíduo que carrega os traços do grupo discriminado constitui inferioridade e faz com que os sujeitos ao preconceito sejam sistematicamente preteridos em relação aos demais.

No que diz respeito à democracia racial, seus precursores e seus atuais defensores, nos parece aceitável afirmar que é uma teoria amplamente disseminada desde o campo científico até sua divulgação mais geral nas mídias e no imaginário popular. Diante do exposto até aqui, verificamos que é possível perceber que a raiz da discussão sobre temas afirmativos está nas teses e contrateses em torno da democracia racial desde Gilberto Freyre (2004) e Nina Rodrigues (1984). Se observarmos as questões da ideologia do mulato, ou poderíamos dizer pardo, e dos termos do assimilacionismo, a crítica à democracia racial aparece desta forma em Ribeiro (2006):

As atuais classes dominantes brasileiras, feitas de filhos e netos dos antigos senhores de escravos, guardam, diante do negro, a mesma atitude de desprezo vil. Para seus pais, o negro escravo, o forro, bem como o mulato, eram mera 
força energética, como um saco de carvão, que desgastado era facilmente substituído por outro que se comprava. Para seus descendentes, o negro livre, o mulato e o branco pobre são também o que há de mais reles, pela preguiça, pela ignorância, pela criminalidade inatas e inelutáveis. Todos eles são tidos consensualmente como culpados de suas próprias desgraças, explicadas como características da raça e não como resultado da escravidão e da opressão. Essa visão deformada é assimilada também pelos mulatos e até pelos negros que conseguem ascender socialmente, os quais se somam ao contingente branco para discriminar o negro-massa. A nação brasileira, comandada por gente dessa mentalidade, nunca fez nada pela massa negra que a construíra. Negoulhe a posse de qualquer pedaço de terra para viver e cultivar, de escolas em que pudesse educar seus filhos, de qualquer ordem de assistência. Só lhes deu, sobejamente, discriminação e repressão. Grande parte desses negros dirigiuse às cidades, onde encontraram, originalmente, os chamados bairros africanos, que deram lugar às favelas. Desde então, elas vêm se multiplicando, como a solução que o pobre encontra para morar e conviver. Sempre debaixo da permanente ameaça de serem erradicados e expulsos. (RIBEIRO, 2006, p. 221-222)

\section{Conclusões e perspectivas}

Por fim, nosso pensamento exposto neste artigo é uma tentativa, um ensaio, uma perspectiva. Esta frase que inicia a conclusão não diminui a importância e o rigor científico da escrita, mas nos coloca na tarefa de fazer apontamentos e justifica essas quase 30 páginas, ainda insuficientes, dada a complexidade e necessidade do tema.

Dito isso, vamos ensaiar três ou quatro perspectivas de conclusão. 0 debate brasileiro sobre a construção de um Estado brasileiro e/ou de uma nação primeiramente precisa considerar a existência das raças e os desdobramentos de uma sociedade racializada. 0 conceito de raça está colocado como elemento central para o mundo após a expansão marítima e comercial europeia.

O Brasil sempre esteve divido entre brancos e negros, embora nenhum dos grupos seja uníssono ou monocromático, compreendendo negros como todos aqueles que vivem do trabalho do da falta endêmica dele. A categoria negro teve diferentes abordagens ao longo da história, mas englobou sempre os excluídos da sociedade brasileira, apagados do projeto de Estado e de país. Até a enorme variedade de povos indígenas foram chamados de negros da terra, corroborando a ideia de que esta categoria representa um grupo 
extremamente grande e complexo com alguns pontos em comum, dentre eles, a exclusão de qualquer projeto de nação. Não é confirmada cientificamente a ideia de que a categoria negros engloba um gama enorme de grupos, uma vez que o mesmo não é aplicado também para a diversidade da categoria branco.

Embora, este grupo majoritário na sociedade brasileira tenha enorme variedade de rostos, tonalidades, tradições e cosmologias, o que os junta em um mesmo possível balaio é o conceito de raça, nele a categoria negro. Este último não exclui os grupos que considera não brancos, mesmo aqueles com a tonalidade de pele um pouco mais clara.

O falso dilema dos pardos foi uma segunda questão observada. Verificamos que, desde sempre, a raça/cor parda foi a mais permeável das classificações raciais (PIZA e ROSEMBERG, 2012) ora por agrupar um amplo e complexo leque que vai de diversos tipos de não brancos aos pretos, ora por supostamente incluir também os grupos indígenas e todas as misturas possíveis no caldo das raças. Os pardos atuaram como um coringa em uma nação multicolor cujo pertencimento racial, tão atravessado de outras variáveis imbricadas a relações de poder.

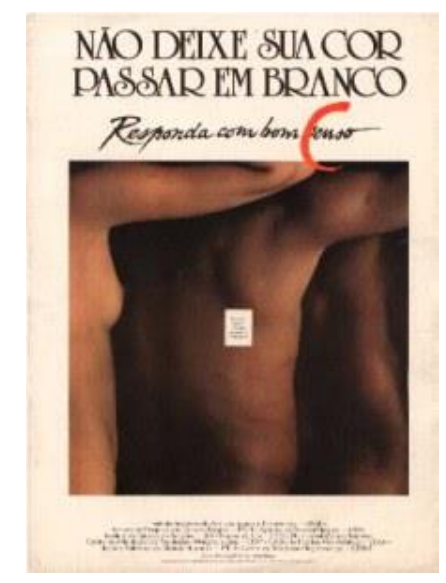

Figura 1 Campanha de afirmação racial desenvolvida por segmentos do movimento negro durante o recenseamento de 1991.

Não à toa, setores do movimento negro lançaram a campanha, durante o recenseamento de 1991, cujo slogan era: "Não deixe sua cor passar em branco", fazendo uma alusão crítica à tendência de branquear-se como tática 
de reconhecimento ou ascensão social. Poderíamos citar uma séria de programas, campanhas, cartilhas e mobilizações do movimento neste sentido, mas escolhemos essa por ser a primeira após a Constituição de 1988, que utilizou as categorias atuais, respeitando o modelo de autodeclaração.

A miscigenação como projeto também disputou os pardos para o lado dos brancos, como vimos. Não só o movimento negro, como afirmam alguns artigos acadêmicos, até porque o projeto político do Estado brasileiro ao fim da Monarquia, desde os primeiros anos da República, foi fazer os negros desaparecerem. Não obtiveram uma vitória concreta e foram para o plano B, dividir os negros em suas diferentes tonalidades de pele, impedindo que se configurassem enquanto grupo e maioria social. Derrotados novamente, a minoria branca brasileira depositou sua energia no fracionismo ou na desconstrução da ideia de população negra como soma de pretos e pardos. Ainda que maioria social nos últimos censos em ascensão, a disputa que visa tirar os pardos da população negra, busca impedir que este maioria social consolidada nos últimos 20 anos possa ser tornar uma bloco histórico, isto é, uma maioria política.

A produção de Carlos Hasenbalg e Nelson do Valle Silva, somados a militância, produção acadêmica e política de Lélia Gonzáles, Abdias do Nascimento, Beatriz do Nascimento constituíram uma tecnologia de resistência ao branqueamento censitário e político do país, gestado de Gilberto Freire e Nina Rodrigues ao Ali Kamel. Estes estudos construíram uma razão histórica rigorosamente científica da equivalência das categorias pretos e pardos como população negra.

A falsa, mas ainda vitoriosa democracia racial brasileira segue aprimorando suas tecnologias de controle da maioria negra brasileira, assim como atravessando principalmente a maioria dos pardos. Como vimos nos estudos de Silva e Leão (2012), apenas uma pequena parte dos pardos consegue se compreender como negro. Esta parte majoritária dos pardos que não responde se entender como população negra nos censo, também não se enxerga como branca, mas tem consciência e afirma sofrer o racismo diariamente. 
Essa massa que já soma mais de $40 \%$ da sociedade brasileira não goza de privilégios, como está provado nos diversos estudos sobre desigualdades raciais já citados. A maioria dos artigos, teses e estudos do tema desconsidera a participação do movimento negro, ou melhor, desconsidera a intelectualidade negra que estava inserida dentro da universidade, mas também no organicamente dentro dos mais diversos setores do movimento negro.

Finalmente, construir a resistência a ideia de democracia racial como tecnologia do racismo brasileiro passa impreterivelmente pela disputa da categoria pardo. Abdias do Nascimento, Lélia Gonzalez e Carlos Hasenbalg compreenderam isso não só para o Brasil, mas para a extensão da Améfrica Ladina. As atuais discussões acerca do tema com base no pensamento identitário pós-moderno pecam na superficialidade das pesquisas que não mais observam a totalidade da realidade. Em nossa análise, do ponto de vista dialético, não é possível falar de raça negra no Brasil, excluindo as relações inter-raciais e o produto delas que já soma mais de um terço do país. A invenção de um Brasil democrático e inclusivo passa pela resistência a assimilação e por um projeto de Estado Nacional plurirracial, como apontou Florestan ao introduzir o livro e pensamento de Abdias do Nascimento (1978). A proposta de resistência ao racismo brasileiro de caráter assimilacionista foi construída há muitas mãos desde a década de 1970 . Intelectuais e militantes do movimento negro, que, ao perceberem, as táticas habilmente construídas pela lógica da democracia racial no caminho do embranquecimento pela metade do nosso povo, propuseram, autorizados por vasta produção e dados científicos, a categoria negro. Dessa construção, saímos enquanto maioria social e embrião de uma maioria política, ainda sob ataque da elite brasileira. Então, pretos e pardos, uni-vos!

\section{Referências}

BENTO, Maria Aparecida Silva. Branquitude e Poder - a questão das cotas para negros. In: SANTOS, Sales Augusto dos (Org.). Ações afirmativas e combate ao racismo nas Américas. Brasília: Ministério da Educação, 
Secretaria de Educação Continuada, Alfabetização e Diversidade, 2005. P. 165-177.

BRASIL. Ministério da Educação. Instituto Nacional De Estudos e Pesquisas Educacionais Anísio Teixeira. Censo da Educação Superior. Brasília. DF: INEP, 2011. COSTA, Tereza Cristina N. Araújo. “O Princípio Classificatório ‘Cor’, sua Complexidade e Implicações para um Estudo Censitário”, in Revista Brasileira de Geografia, v. 36, n. 3, Rio de Janeiro, jul.-set./1974, pp. 91-103. FERNADES, Florestan. A integração do negro na sociedade de classes: (o legado da "raça branca", volume I) - 5. Ed. - São Paulo: Globo 2008.

A Integração do Negro na Sociedade de Classes. São Paulo: Dominus-USP, 1965.

Prefácio à edição brasileira. In: NASCIMENTO, Abdias do. 0 genocídio do negro brasileiro. Rio de Janeiro: Paz e Terra, 1978. FREYRE, Gilberto. Casa-grande \& Senzala: formação da família brasileira sob o regime da economia patriarcal. 49ª Ed. São Paulo: Global, 2004.

GAMA, Zacarias Jaegger; SANTOS, T. L. A. Cotas na Universidade: cooptação ou libertação? Cadernos do GEA. - N.11 (ago./dez. 2020). - Rio de Janeiro: FLACSO, GEA; UERJ, LPP, 2020- v.

GOMES, G. P. S.No peito e na raça: Problemática racial e políticas afirmativas na UERJ. Cadernos do GEA. - N.11 (ago./dez. 2020). - Rio de Janeiro: FLACSO, GEA; UERJ, LPP, 2020- v. GRAMSCI, Antonio. A Concepção dialética da história. 5. ed., Rio de Janeiro, Civilização Brasileira, 1984.

GUERREIRO RAMOS, Alberto. O negro no Brasil e um exame de consciência. In: NASCIMENTO, Abdias et al. Relações de raça no Brasil. Rio de Janeiro, Quilombo, 1950.

O problema do negro na sociologia brasileira. Cadernos do Nosso Tempo, 2, jan./jun, 1954.

IBGE. Censo Demográfico 2010. Disponível em: <https://censo2010.ibge.gov.br/> Acesso em: 20/10/2020. GONZALEZ, Lélia; HASENBALG, Carlos. Lugar de negro. São Paulo: Marco Zero, 1982.

HASENBALG, Carlos. 2005[1979]. Discriminação e Desigualdades Raciais no Brasil. Belo Horizonte e Rio de Janeiro: Editora da UFMG e IUPERJ. IENSUE, Geziela. Políticas de cotas raciais em universidades brasileiras: entre a legitimidade e a eficácia. Curitiba. Juruá Editora: 2010. 
KAMEL, Ali. Não somos racistas: uma reação aos que querem nos transformar numa nação bicolor. Rio de Janeiro: Nova Fronteira, 2006.

MEDEIROS, Carlos Alberto. Ação afirmativa no Brasil: um debate em curso. In: SANTOS, Sales Augusto dos. Ações afirmativas e combate ao racismo nas Américas. Brasília, DF: Ministério da Educação, Secretaria de Educação Continuada, Alfabetização e Diversidade, 2005. P. 121-141.

MOURA, Clóvis. 0 negro: de bom escravo a mau cidadão? Editora Conquista, RJ, 1977.

MUNANGA, Kabengele. Negritude: Usos e Sentidos. $2^{\underline{a}}$ ed. São Paulo: Ática, 1988.

O Anti-racismo no Brasil. In: MUNANGA, K. (org.). Estratégias e políticas de combate à discriminação racial. São Paulo: Edusp, 1996. Rediscutindo a mestiçagem no Brasil: identidade nacional versus identidade negra. Belo Horizonte: Autêntica, 2006. NASCIMENTO, Abdias do. o Genocídio do Negro Brasileiro. Rio de Janeiro: Paz e Terra, 1978.

O quilombismo. Petrópolis: Editora Vozes, 1980.

NOGUEIRA, Oracy. Tanto preto quanto branco: estudo de relações raciais. São Paulo: T. A. Queiroz, 1985.

OSÓRIO, Rafael G. 0 sistema classificatório de cor ou raça do IBGE. Brasília. Texto para discussão Ipea, 2003. Disponível em: < http://www.ipea.gov.br/portal/index.php?option=com_content\&view=arti cle\&id $=4212>$ Acesso em 20/10/2020.

PEREIRA, Amauri M. Trajetória e Perspectivas do Movimento Negro Brasileiro. Belo Horizonte: Editora Nandyala, 2008.

PIZA, E.; ROSEMBERG, F. Cor nos censos brasileiros. In: CARONE, I; BENTO, M. A. S. (Org.). Psicologia social do racismo: estudos sobre branquitude e branqueamento no Brasil. Petrópolis, RJ: Vozes, 2012. p. 91120.

SILVA, Graziella Moraes; LEÃO, Luciana de Souza. (2012), “O Paradoxo da Mistura: Identidades, Desigualdades e Percepção de Discriminação entre Brasileiros Pardos". Revista Brasileira de Ciências Sociais, vol. 27, no 80 , p. $117-133$

SILVA JR., Hédio. Direito de Igualdade Racial: Aspectos Constitucionais, Civis e Penais. São Paulo: Juarez de Oliveira, 2002. SILVA, Nelson do Valle (1978). Black-white income differentials in Brazil, 1960. Doutorado, Sociologia, Universidade de Michigan, Michigan 
SILVA, Nelson do Valle. 1981. Cor e o processo de realização

socioeconômica. Dados, v. 24, n.3, pp.391-409. HASENABLG, Carlos \& SILVA, Nelson do Valle. 1999. Educação e diferenças raciais na mobilidade ocupacional no brasil. In: HASENABLG, Carlos; VALLE SILVA, Nelson do \& LIMA, Marcia. Cor e Estratificação Social. Rio de Janeiro: Contracapa, pp.218-231.

SOUZA, Duílio Duka de. Combate ao racismo: compromissos e ações positivas. In: PINSKY, Jaime (Org.). Práticas de cidadania. São Paulo: Contexto, 2004.

TELLES, Edward. Racismo à Brasileira. Uma nova perspectiva sociológica. 1aed. Rio de Janeiro: Dumará, 2003.

TODOROV, Tzvetan. Nós e os outros. A reflexão francesa sobre a diversidade humana. Rio de Janeiro. Jorge 